\title{
The Ant Genus Sphinctomyrmex Mayr (Hymenoptera, Formicidae, Cerapachyinae) in the Neotropical Region, with the Description of Two New Species
}

\author{
Rodrigo M. Feitosa, ${ }^{1}$ Carlos Roberto F. Brandão, ${ }^{1}$ \\ Fernando Fernández, ${ }^{2}$ and Jacques C. H. Delabie ${ }^{3,4}$ \\ ${ }^{1}$ Museu de Zoologia da Universidade de São Paulo, Avenida Nazaré 481, Ipiranga, \\ 04263-000 São Paulo, SP, Brazil \\ ${ }^{2}$ Instituto de Ciencias Naturales, Universidad Nacional de Colombia, Carreira 30, No. 45-03, Apartado 7495, \\ Bogotá, DC, Colombia \\ ${ }^{3}$ Laboratório de Mirmecologia, Centro de Pesquisas do Cacau (CEPEC/CEPLAC), Caixa Postal 7, \\ 45600-000 Itabuna, BA, Brazil \\ ${ }^{4}$ Departamento de Ciências Agrárias e Ambientais, Universidade Estadual de Santa Cruz, Km 16 Rodovia Ilhéus-Itabuna, \\ 45650-000 Ilhéus, BA, Brazil
}

Correspondence should be addressed to Rodrigo M. Feitosa, rfeitosa@usp.br

Received 20 May 2011; Accepted 13 June 2011

Academic Editor: Jonathan D. Majer

Copyright ( $) 2012$ Rodrigo M. Feitosa et al. This is an open access article distributed under the Creative Commons Attribution License, which permits unrestricted use, distribution, and reproduction in any medium, provided the original work is properly cited.

The ant genus Sphinctomyrmex has been represented in the Neotropical Region until now by a single species, S. stali, known only from sparse localities in southeastern Brazil. Two new neotropical species are herein described, S. marcoyi sp. n. and S. schoerederi sp. n. from workers collected in the Brazilian Amazon and Atlantic Forest, respectively. New records for Sphinctomyrmex stali are presented, and the species is redescribed together with discussions on its high morphological variation and the identity of its type specimen. A key for the neotropical Sphinctomyrmex workers, images of all species presently known, and a distribution map are supplied.

\section{Introduction}

Sphinctomyrmex is a pantropical and distinctive group of cerapachyine ants, originally described by Mayr [1] with $S$. stali as its type species by monotypy, based on a single gyne collected in Brazil. Borgmeier [2] provided taxonomic notes and described the worker caste of S. stali. Brown [3] revised the genus and provided an identification key for the species known at that time.

Morphologically, the genus is characterized by the unique arrangement of the gastric segments, which are nearly equal in length and separated from each other by distinct constrictions. Sphinctomyrmex is best represented in number of species in the Indo-Australian region compared to other parts of the world [4]. Until now, this genus remained known in the Neotropical region only by the rarely collected S. stali.

Very little is known on the natural history of Sphinctomyrmex. The few observations so far suggest that ants of this genus are nomadic predators of other ants $[3,5,6]$.

Recent surveys of leaf litter ants in Brazilian biomes revealed several Sphinctomyrmex specimens, extending considerably the known distribution range of the genus. Moreover, these surveys have yielded specimens that do not fit the $S$. stali diagnosis and which are here described as two new species. In addition, we redescribe $S$. stali commenting on its extreme morphological variation and the identity of its type specimen. We hope that this paper will encourage further examination and revision of this biogeographically interesting ant genus. 


\section{Material and Methods}

Observations were made at $60 \mathrm{x}$ magnification with a Leica MZ95 stereomicroscope. Measurements were made with a micrometer and recorded to the nearest $0.01 \mathrm{~mm}$. Ranges between brackets are always presented as minimum-maximum values. All measurements are given in millimeters, and the abbreviations used are:

HL: head length - the maximum measurable length of head capsule excluding mandibles, measured in full-face view, in a straight line from the mid-point of the anterior clypeal margin to the midpoint of the vertexal margin;

HW: head width - the maximum width of the head capsule measured in full-face view, excluding the compound eyes;

SL: antennal scape length-the chord length of the antennal scape, excluding the basal condyle and its peduncle;

EL: eye length—the maximum measurable length of eyes in profile;

WL: mesosomal length (Weber's length) - the diagonal length of mesosoma in profile, from the midpoint of the anterior pronotal declivity to the posterior margin of the propodeal lobes;

PL: petiole length-in dorsal view, the maximum length of the petiole;

PW: petiole width—in dorsal view, the maximum width of the petiole;

GL: gaster length - the maximum length of gaster in lateral view, excluding the sting;

TL: total length—the summed length of HL, WL, PL, and GL;

CI: cephalic index-HW $\times$ 100/HL;

SI: scape index-SL $\times 100 / H W$;

OI: ocular index-EL $\times 100 / \mathrm{HW}$;

Depository collections are referred to by the following acronyms.

CPDC: Centro de Pesquisas do Cacau, Itabuna, BA, Brazil;

MCZC: Museum of Comparative Zoology, Harvard University, Cambridge, Mass, USA;

MZSP: Museu de Zoologia da Universidade de São Paulo, São Paulo, SP, Brazil;

NHRS: Naturhistoriska Riksmuseet, Stockholm, Sweden;

UFV: Laboratório de Ecologia de Comunidades, Universidade Federal de Viçosa, Viçosa, MG, Brazil.

High resolution digital images of Sphinctomyrmex schoerederi sp. n. and S. stali (workers) are here presented thanks to the kind permission of Dr. B. L. Fisher (California Academy of Sciences). These images are available at the AntWeb webpage (http://www.antweb.org/). Images of Sphinctomyrmex marcoyi sp. n. and S. stali (gyne) were obtained under a stereomicroscope Leica M205C attached to a video camera Leica DFC 295. The photos were then combined using the software Leica Application Suite V3.Ink. Combined photos were edited in PhotoShop (Adobe) to enhance parameters of brightness and contrast. The distribution map was generated by the software Quantum GIS 1.5.0 (Tethys) with coordinates imported from Google Earth (Google).

The terms for external morphology and surface sculpturing follow, respectively, [7], [8]. The reproductive females are here called "gynes" [9].

\section{Results}

\subsection{Revised Diagnosis for the Neotropical Species of Sphinctomyrmex}

3.1.1. Sphinctomyrmex Mayr, 1866. Sphinctomyrmex Mayr, 1866: 895. Type species: Sphinctomyrmex stali, by monotypy. (for the complete taxonomic synopsis, see [4]).

Worker. Size highly variable (TL 2.04-4.64). Body yellowish to black, commonly reddish-brown, with appendages slightly lighter. Pilosity relatively dense, composed mainly by long whitish hairs, which are suberect on head, mesosoma, and petiole, and subdecumbent on the gaster dorsum; appendages densely covered by short suberect hairs; antennal funiculi and leg tarsomeres with dense pubescence. Mandibular surface smooth, with sparse piligerous punctures; antennal scapes densely punctuate; body dorsum variably foveolate, with a single filiform hair projected from each fovea; declivous face of propodeum smooth to faintly areolate; dorsal surface of pygidium shallowly and densely areolate.

Head as long as to longer than broad; posterior margin mostly straight with a discrete median concavity; mandibles subtriangular, without intramandibular space when fully closed; mandibular dentition inconspicuous; antennae with 12 segments; antennal scapes clavate, distinctly curved at the base and relatively short; funicular segments length gradually increasing towards the apex; eyes strongly reduced to vestigial.

Mesosoma subrectangular in lateral view, relatively elongate, with a flat and continuous dorsal profile; inferior corners of pronotum rounded; anepisternum and katepisternum separated by a distinct suture; dorsal and posterior margins of propodeum meeting in a distinct angle, never projected as teeth or spines; propodeal spiracles set very low in the segment, bellow the midheight of propodeum in lateral view, with the opening directed posterad; propodeal lobes well developed and subquadrate; declivous face of propodeum straight in lateral view.

Petiole not pedunculate, slightly higher than long in lateral view, with dorsal face weakly convex; in dorsal view, petiole barely longer than broad; subpetiolar process developed, rounded apically, and in general with a conspicuous elliptical to rounded fenestra. In dorsal view, first gastral segment 
(abdominal III) notably narrower than the posterior ones, separated from the second gastral segment (abdominal IV) by a wide and deep constriction; abdominal segment IV with a relatively large pretergite; segments V to VII nearly equal in length, separated from each other by distinct constrictions.

Gyne. See comments under S. stali description.

\subsection{Identification Key to Neotropical Species of Sphinctomyrmex (Workers).}

(1) Size relatively small ( $\mathrm{HW}<0.40 \mathrm{~mm}$ ); head notably elongate $(\mathrm{CI}<70)$; dorsum of mesosoma with a median longitudinal smooth stripe (Brazil: AM) ... S. marcoyi sp. n.

- Size relatively large (HW $>0.40 \mathrm{~mm}$ ); head moderately elongate to subquadrate $(\mathrm{CI}>70)$; dorsum of mesosoma without a median longitudinal smooth stripe ... (2)

(2) Head slightly to considerably elongate; clypeus narrowly inserted between the frontal lobes, so that the frontal carinae are placed close to each other (Figures 2(a) and 2(d)); lateral lobes of the anterior margin of clypeus absent or vestigial; abdominal segments IV to VII with comparatively short pretergites; gastral dorsum devoid of appressed hairs (Brazil: BA, MG, RJ, SC, SP) ... S. stali Mayr

- Head distinctly subquadrate; clypeus broadly inserted between the frontal lobes, so that the frontal carinae are well separated from each other (Figure 1(d)); anterior margin of clypeus with two lateral lobes projecting over the mandibles; abdominal segments IV to VII with strongly developed pretergites; gastral dorsum with short appressed hairs (Brazil: MG) ... S. schoerederi sp. n.

\subsection{Species Accounts}

\subsubsection{Sphinctomyrmex marcoyi sp. n. (Figures 1 and 4).}

Holotype Worker. Brazil. Amazonas; Manaus, Rs 2206; in soil, 01.11.1993; A.B. Casimiro col. no. 6 (4832) [CDPC].

Diagnosis. Sphinctomyrmex marcoyi can be easily separated from other species in the genus by its comparatively diminutive size (HW $<0.40 \mathrm{~mm}$, TL $<3.00 \mathrm{~mm}$ ), conspicuously elongate head, comparatively short scapes, and by the presence of a smooth longitudinal stripe on the dorsum of mesosoma, which is otherwise covered by foveolae and subdecumbent to erect hairs.

Holotype Measurements. HL 0.53; HW 0.35; SL 0.21; EL 0.025; WL 0.61; PL 0.23; PW 0.21; GL 1.24; TL 2.04; CI 66; SI 60; OI 7.14.

Worker Description. Relatively small size (TL about 2.00 $\mathrm{mm}$ ). Body reddish-brown with slightly lighter appendages.
Body dull; dorsum of mesosoma and petiole shiny. Pilosity comparatively dense; dorsum of head with short suberect to subdecumbent hairs; dorsum of mesosoma with short suberect hairs and a few long, sparsely distributed erect hairs, except for a longitudinal median stripe devoid of pilosity; petiole densely covered by suberect hairs; gastral dorsum with short appressed hairs mixed with sparse, longer hairs. Posterior area of head (nuchal area) opaque; dorsum of body densely foveolate; dorsum of mesosoma with a longitudinal, smooth, and shining, median stripe; sides of mesosoma and petiole with faint irregular reticulation; declivous face of propodeum without discernible sculpture; dorsal surface of the apical segments of gaster finely foveolate, the foveolae separated by wide interspaces (wider than the foveolae).

Head elongate (CI 66), slightly broader anteriorly; lateral margins faintly convex; clypeus narrowly inserted between the frontal lobes; anterior margin of clypeus devoid of lateral lobes, with a distinct median incision; antennal scapes short, with the apices well below the level of eyes; antennal club formed only by the apical segment, which is longer than the four preceding segments combined; eyes strongly reduced, as small as or smaller than the adjacent foveae of the head surface, with two small facets at it's maximum diameter. In dorsal view, lateral margins of mesosoma subparallel; pronotum with evenly rounded humeral corners; promesonotal suture not impressed dorsally. In dorsal view, petiole slightly longer than broad, with lateral margins slightly divergent; subpetiolar process moderately developed. Abdominal segments IV to VII with short pretergites, separated from each other by deeply impressed, short constrictions.

Gyne. Unknown.

Male. Unknown.

Etymology. The specific epithet honors Laurent Saint-Cricq (1815-1888), who published several papers and books between 1853 and 1876 on his voyages to South America (under the pseudonym of Paul Marcoy or Paul de Carmoy). His writings were particularly humanistic and naturalistic; his most important book is "Voyage à travers l'Amérique du Sud, de l'Océan Pacifique à l'Océan Atlantique" published in 1869 and translated into different languages.

Comments. Sphinctomyrmex marcoyi is known only from the holotype. The specimen was collected from a soil sample (25 cm depth). Nothing is known about its biology. As far as we know this is the only Sphinctomyrmex species recorded in the Amazon Forest [10], extending the distribution range of the genus more than $2,500 \mathrm{~km}$ to the north-west.

\subsubsection{Sphinctomyrmex schoerederi sp. n. (Figures 1 and 4).}

Holotype Worker. Brazil. Minas Gerais; Viçosa; ii.1994; Sperber, Louzada and Lopes cols [MZSP].

Diagnosis. This species can hardly be confounded with other congeners given the combination of subquadrate head, 


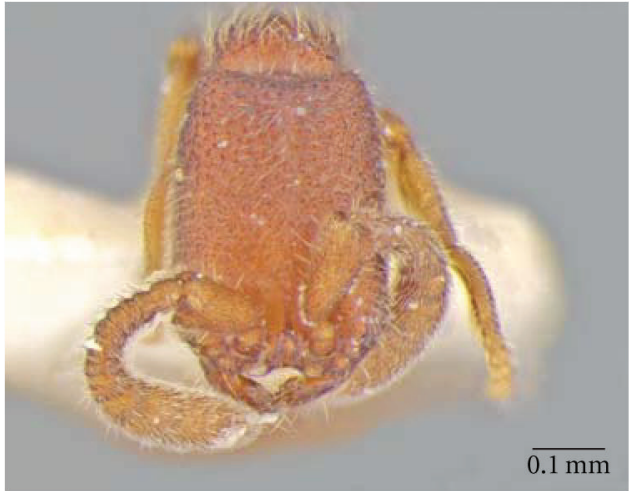

(a)

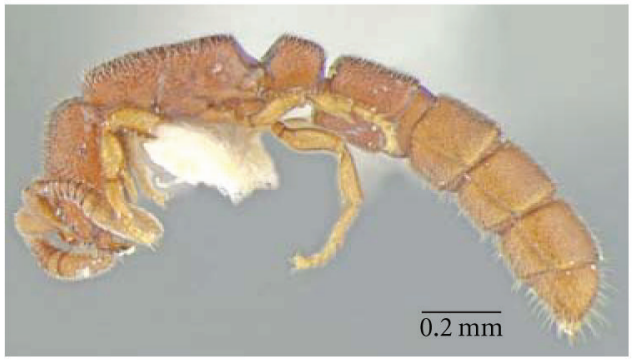

(b)

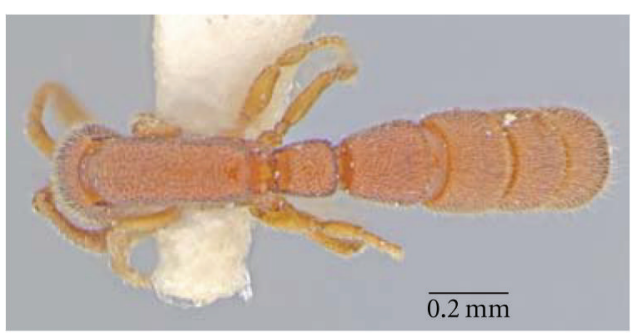

(c)

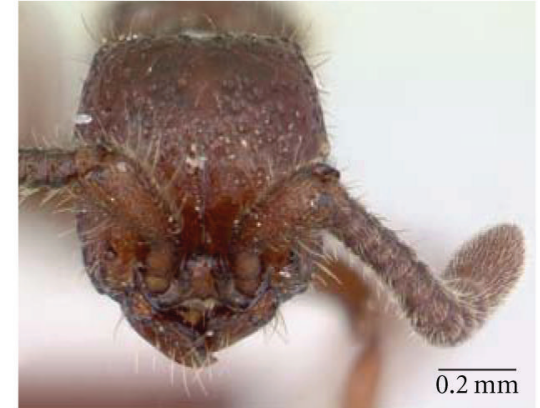

(d)

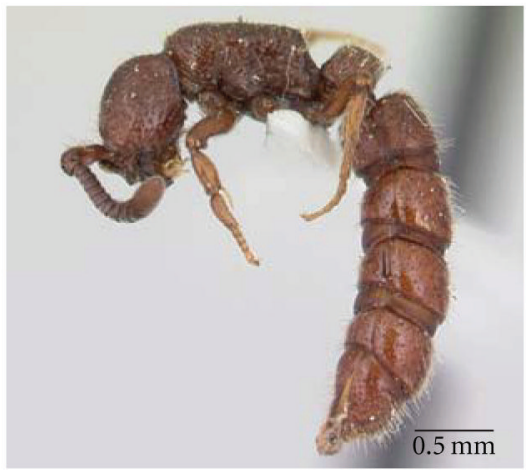

(e)

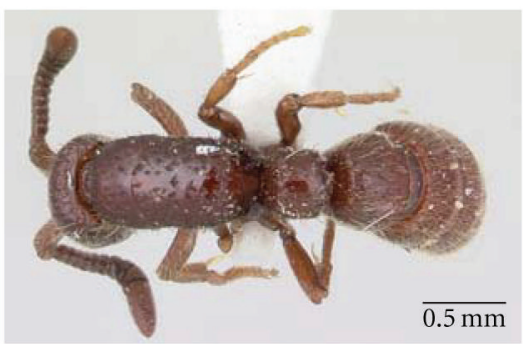

(f)

FIgure 1: Sphinctomyrmex marcoyi. (a)-(c): Holotype worker from Manaus, AM, Brazil: (a) head in full face view, (b) lateral view, (c) dorsal view. Image by Ricardo Kawada, specimen CPDC 6(4832). Sphinctomyrmex schoerederi. (d)-(e): Holotype worker from Viçosa, MG, Brazil: (d) head in full face view, (e) lateral view, (f) dorsal view. Image by April Nobile, specimen CASENT 0178849.

anterior margin of clypeus with two lateral lobes projecting over the mandibles, abdominal segments IV to VII with strongly developed pretergites, and the presence of short appressed hairs on the dorsal surface of gaster.

Holotype Measurements. HL 0.72; HW 0.65; SL 0.43; EL 0.05; WL 1.01; PL 0.44; PW 0.41; GL 2.31; TL 4.48; CI 90.11; SI 65.81; OI 7.32 .

Worker Description. Size comparatively large (TL $4.48 \mathrm{~mm}$ ). Body reddish-brown with appendages slightly lighter. Pilosity dense; gaster covered by short appressed hairs.

Posterior area of head (nuchal area) smooth and shiny; body dorsum foveolate; space between the foveae mostly smooth, with fine longitudinal striation on the anterior portion of head; declivous face of propodeum shallowly punctuate-reticulate; sides of mesosoma and petiole strongly sculptured, with shallow foveae and irregular reticulation; sides of gaster predominantly smooth and shiny, with a few coarse punctures.

Head subquadrate (CI 90.11); lateral margins gently convex; clypeus broadly inserted between the frontal lobes, so that the frontal carinae are well separated from each other; anterior margin of clypeus with two lateral lobes projecting over the mandibles; antennal scapes reaching the level of eyes; apical segment of antennae longer than the three preceding ones together; antennal club formed only by the apical segment; eyes strongly reduced, as large as the adjacent foveae of head surface, with about three small facets at its maximum diameter. In dorsal view, lateral margins of mesosoma convex; pronotum with humeral corners rounded; promesonotal suture distinct in dorsal view but not impressed. In dorsal view, petiole a little longer than broad, with lateral margins slightly divergent; subpetiolar process 


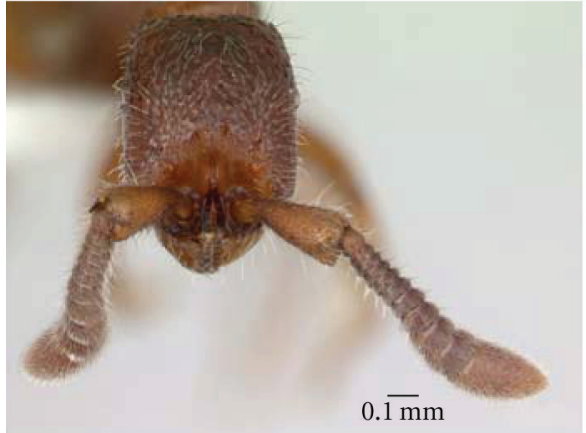

(a)

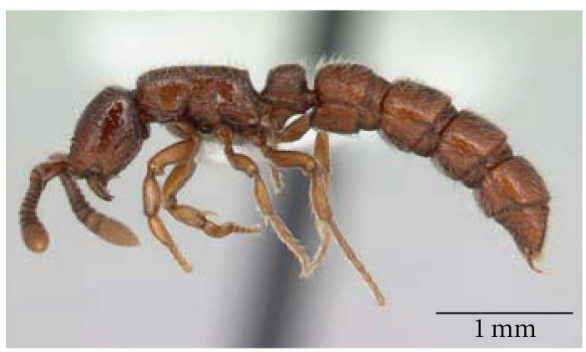

(b)

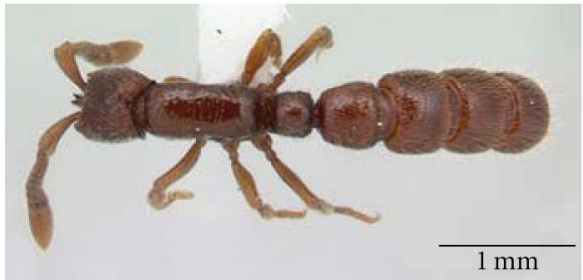

(c)

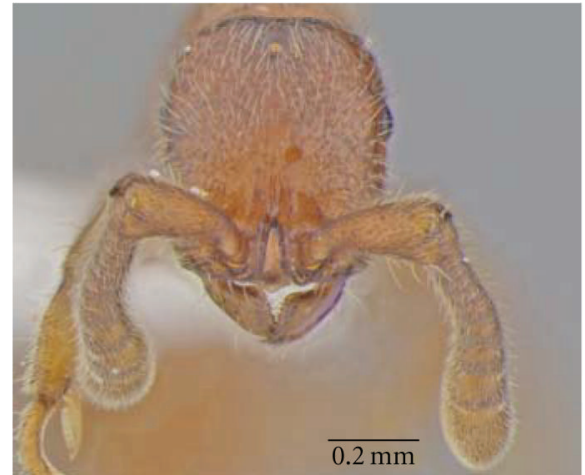

(d)

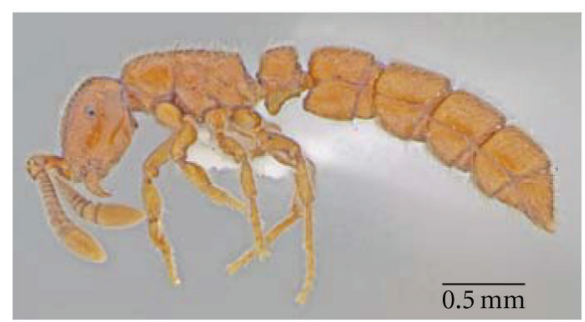

(e)

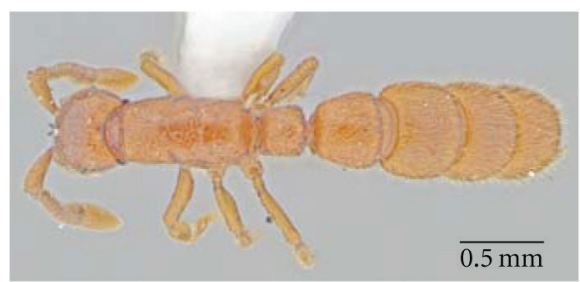

(f)

FIGURE 2: Sphinctomyrmex stali. (a)-(c): worker of morphotype 1 from São Bonifácio, SC, Brazil (a) head in full face view, (b) lateral view, (c) dorsal view. Image by Michele Esposito, specimen CASENT 0178866. (d)-(f): ergatoid from São Bento do Sul, SC, Brazil (d) head in full face view, (e) lateral view, and (f) dorsal view. Image by Ricardo Kawada.

moderately developed. Abdominal segments IV to VII with strongly developed pretergites, separated from each other by comparatively shallow and wide constrictions.

Gyne. Unknown.

Male. Unknown.

Etymology. The specific epithet honors our colleague Dr. José Henrique Schoereder, a prominent ant ecologist working at Universidade Federal de Viçosa, MG, Brazil. Dr. Schoereder kindly allowed us to describe this species formerly deposited in the ant collection of his laboratory.

Comments. Sphinctomyrmex schoerederi is known only from the holotype. The specimen was collected in a leaf litter sample from a forest remnant in the campus of Universidade Federal de Viçosa, MG, Brazil, where it occurs in sympatry with S. stali. Nothing is known about its biology.
3.3.3. Sphinctomyrmex stali Mayr, 1866 (Figures 2, 3, and 4). Sphinctomyrmex stali G. Mayr, 1866: 895, pl. 20, Figure 8. Holotype gyne: Brazil, Rio de Janeiro, F. Sahlberg coll., HEVA000000012 [NHRS] (high-resolution images examined); Borgmeier [2, page 105], (distribution records and worker description); Brown [3], (world revision and key to species).

Diagnosis. The distinctly elongate head, the narrow insertion of the clypeus between the frontal lobes, the absence of lateral lobes from the anterior margin of clypeus, and the absence of appressed hairs on the dorsum of gaster separate $S$. stali from S. schoerederi. This species can be separated from S. marcoyi by its much larger size and the absence of a median smooth longitudinal stripe on the dorsum of mesosoma.

Worker Measurements $(n=20)$. HL $(0.60-0.79)$; HW $(0.44-$ $0.68)$; SL (0.31-0.50); EL (0.02-0.08); WL (0.71-1.12); PL $(0.28-0.43)$; PW (0.29-0.41); GL (1.66-2.39); TL (3.334.64); CI (71.79-86.00); SI (68.42-77.50); OI (3.33-12.50). 


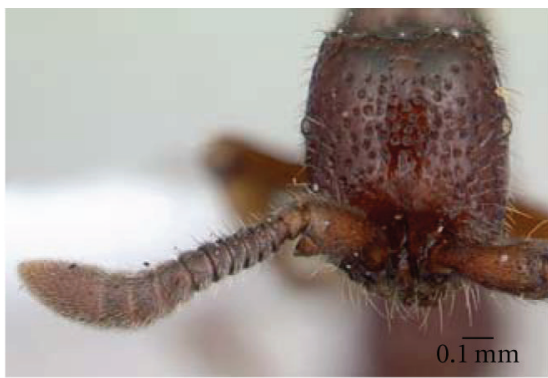

(a)

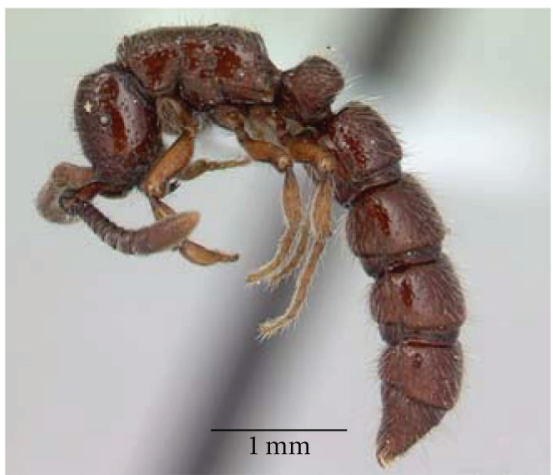

(b)

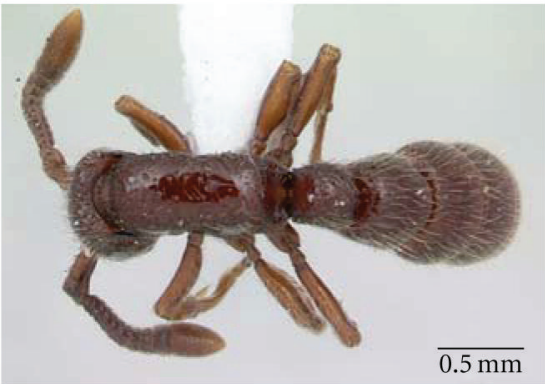

(c)

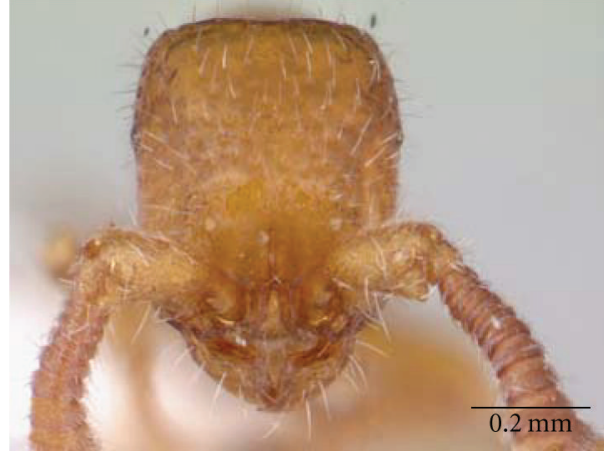

(d)

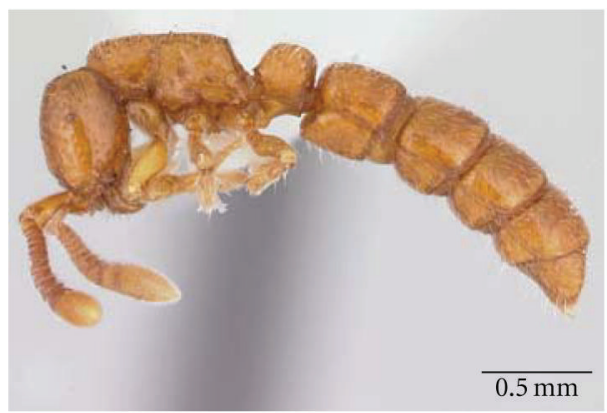

(e)

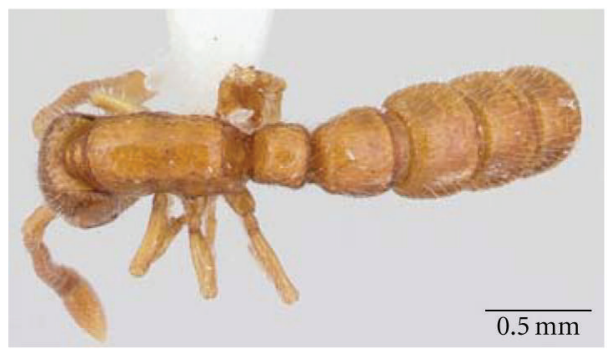

(f)

FIGURe 3: Sphinctomyrmex stali. (a)-(c): worker of morphotype 2 from Ubatuba, SP, Brazil (a) head in full-face view, (b) lateral view, and (c) dorsal view. Image by Michele Esposito, specimen CASENT 0178865. (d)-(f): worker of morphotype 3 from Viçosa, MG, Brazil (d) head in full-face view, (e) lateral view, (f) dorsal view. Image by April Nobile, specimen CASENT 0178850.

Worker Description. Size highly variable (TL 3.33-4.64). Body yellowish to black, commonly reddish-brown with slightly lighter appendages. Pilosity dense; gaster devoid of appressed pilosity. Posterior area of head (nuchal area) smooth to coarsely striate; dorsum of body sparsely foveolate; space between the foveae predominantly smooth and shiny; declivous face of propodeum smooth and shiny to shallowly punctuate-reticulate; sides of meso- and metasoma predominantly smooth and shiny, with a few coarse punctures.

Head slightly to considerably longer than broad, (CI 71.79-86.00); lateral margins subparallel to gently convergent; clypeus narrowly inserted between the frontal lobes, so that the frontal carinae are close to each other; lateral lobes of the anterior margin of clypeus absent or vestigial; antennal scape apices not reaching the level of the compound eyes; apical segment of antennae as long as the three preceding sgments combined; antennal club formed by the apical segment or by the two apical segments; compound eyes strongly reduced to vestigial, as large as or slightly larger than the adjacent foveae of head surface. In dorsal view, lateral margins of mesosoma subparallel; pronotum with humeral corners angled but not forming teeth or spines; promesonotal suture distinct to vestigial in dorsal view, not impressed. In dorsal view, petiole as long as to gently longer than broad with lateral margins feebly divergent; subpetiolar process well developed. Abdominal segments IV to VII with relatively short pretergites, separated from each other by deeply impressed, short constrictions.

Gyne (Ergatoid) Measurements $(n=3)$. HL (0.66-0.68); HW (0.52-0.55); SL (0.36-0.38); EL (0.08-0.11); WL (0.910.98); PL (0.36-0.41); PW (0.32-0.36); GL (1.95-2.17); TL (3.89-4.20); CI (78.57-81.40); SI (65.71-72.73); OI (15.1520.00). 


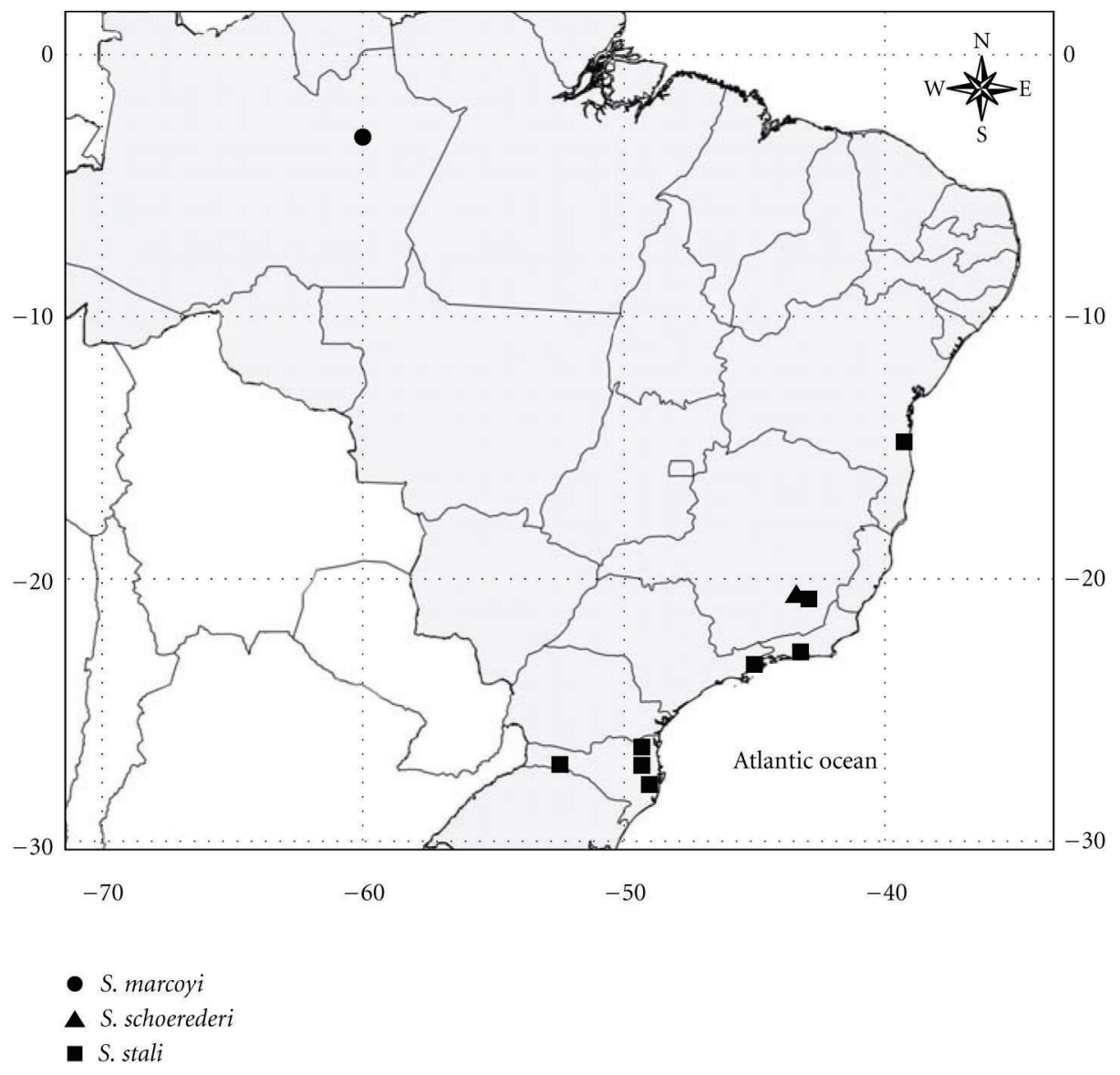

Figure 4: Distribution map for the neotropical species of Sphinctomyrmex.

Gyne Description. Two forms are recognized, alates and ergatoids (but see comments below). The alate form is known from a single specimen, the holotype. This gyne differs from workers by the typical characters expected for ant reproductive females: size significantly larger (TL ca. 6.00); ocelli well developed; compound eyes considerably large, occupying almost one third of the lateral margin of head. Pronotumis well developed, without projections; scutum large and trapezoidal; notauli shallow, almost indistinct; parapsidial lines feebly visible and convergent towards scutellum; scutoscutellar sulcus impressed; scutellum relatively narrow and set at the same level as the scutum, in lateral view; propodeum large in dorsal view, with dorsal face meeting the declivous face in a blunt angle; wings unknown. Petiole and gaster comparatively larger than in conspecific workers.

The ergatoids (Figures 2(d)-2(f)) differ from the conspecific workers only by the presence of three equally developed ocelli and by the compound eyes being comparatively well developed (OI 15.15-20.00).

\section{Male. Unknown.}

Etymology. Dr. Gustav Mayr named this species after the Swedish entomologist Dr. Carl Stål (1833-1878), who was a professor of the Zoological Department of the Royal Swedish
Museum of Natural History in Stockholm. Although he published mostly on Hemiptera and was regarded as its world's foremost scholar, Dr. Stål also published on Orthoptera and to a lesser extent on Coleoptera and Hymenoptera.

Variation. At least three different morphotypes of this highly variable species can be distinguished. Categorization of these morphotypes is somewhat arbitrary as they are not entirely distinct from each other. Therefore, they are not to be recognized as distinct units, but rather as belonging to a gradient. The following comparison, however, simplifies the description of morphological variation and allows for the recognition of possible geographic patterns.

Morphotype 1 (Figures 2(a)-2(c)). Medium size (HW 0.480.55 , TL 3.51-4.00). Color reddish-brown to blackish. Posterior area of head (nuchal area) predominantly smooth and shiny. Head distinctly longer than broad (CI 75.5081.40), with lateral margins weakly convex; eyes reduced but distinctly larger than the adjacent foveae of head surface. Promesonotal suture distinct in dorsal view.

This morphotype conforms most closely with the first workers described for this species [2]. Despite its distribution being restricted to scattered localities in the state of Santa 
Catarina, southern Brazil, it is the most common morphotype of S. stali in museum collections.

Morphotype 2 (Figures 3(a)-3(c)). Large size (HW 0.60-0.69, TL 4.05-4.64). Color reddish to dark brown. Posterior area of head (nuchal area) predominantly smooth and shiny. Head moderately longer than broad (CI 81.63-86.00), with lateral margins weakly convex; eyes reduced but distinctly larger than the adjacent foveae of head surface. Promesonotal suture variably impressed in dorsal view.

In his initial description of S. stali workers [2], the author stated: "...The specimens collected in October 3, 1953 are somewhat larger than the other ..." We examined these workers mentioned by Borgmeier; in fact, they are considerably larger than the other workers, and even larger than the ergatoids examined here. However, except for the exceptional size, the individuals of this morphotype are very similar to those of morphotype 1. Additional workers of morphotype 2 were collected in the Brazilian states of Bahia, Minas Gerais, and São Paulo.

Morphotype 3 (Figures 3(d)-3(f)). Small size (HW 0.440.47, TL 3.33-3.41). Color pale yellow to reddish-brown. Posterior area of head (nuchal area) irregularly striate, with sparse punctures. Head notably longer than broad (CI 71.7975.00), with lateral margins subparallel; eyes vestigial, feebly convex; in some cases only discernable by a dark spot on the sides of head, of the same size as the adjacent foveae of the head surface. Promesonotal suture obsolete, almost indistinct in dorsal view.

This is the most distinctive morphotype of S. stali, known so far only from Viçosa, state of Minas Gerais, southeastern Brazil where it occurs in sympatry with $S$. schoerederi.

Comments. Mayr [1] described Sphinctomyrmex with S. stali as its type species, based on a single dealate gyne. However, except for the holotype, there are no records of normal (alate) gynes for S. stali. All reproductive females collected after the original description are ergatoids. Dr. H. Vårdal, Hymenoptera curator of the NHRS collection, kindly sent us images of the S. stali holotype. We confirm that it is a typical dealate ant gyne given the wing scars and the structure of mesosoma. Therefore, there are at least three possibilities: (1) Sphinctomyrmex stali can possess both forms of reproductive females, alates and ergatoids, as already recorded for other ant species $[11,12$, Christian Peeters (pers.com.)]; (2) our current conception of $S$. stali includes more than a single species, not entirely distinguishable by morphology, and each species may present a different gyne form, or (3) the initial suspicion by Brown (see below) may prove correct, and the Brazilian locality record for the dealate gyne designated as holotype by Mayr may be in error. Hypotheses 1 and 2 seem to be the more plausible based on the label information of the type specimen. The collector of the type, the Finish entomologist Reinhold Ferdinand Sahlberg, probably captured this specimen while collecting insects in his visit to Rio de Janeiro in the middle 1800's [R.F. Sahlberg's field book; Hege Vårdal (pers.com.)]. Incidentally, this possibility is supported by Kempf's decision [13] to treat Rio de Janeiro as the type locality of Sphinctomyrmex stali. The nature of S. stali reproductive females will only be solved with the collection of additional material associated with workers.

Sphinctomyrmex stali is known from sparse localities along the southeastern portion of the Brazilian Atlantic Forest, from Santa Catarina to southern Bahia. Recent collections suggest that this species can be most commonly found in submontane forests (above $600 \mathrm{~m}$ ) of the states of Santa Catarina and São Paulo, from whence come most of the specimens in collections. In correspondence between William Brown Jr. and Father Thomas Borgmeier in 1954 [2], Brown mentions: "The thing that really surprised me about the paper was your mention of Plaumann's discovery of Sphinctomyrmex in Santa Catarina! As matter of fact, I have just finished examining the type of S. ståli [SIC] Mayr (Stockholm Museum), and just send it back to Sweden. I had concluded that the Brazilian locality must be in error, but if your specimens are the same, then I must revise my opinion! I could discover no characters of generic significance between S. ståli and the known winged females of certain Australian "Notosphinctus", and I tentatively conclude that these two names are synonyms. I have seen the type of furcatus Emery, from Burma, and also a winged female of a species (undescribed?) marked as from "Sierra Leone/Afzelius" which is surely of the same genus as ståli on female characters alone, but which is blackish in color ...."

In a single leaf-litter sample collected in São Bonifácio, Santa Catarina, six workers and two ergatoids, very similar to the workers, were captured, which suggests that $S$. stali is polygynous, as already described for other Sphinctomyrmex species $[3,6]$.

Material Examined. Brazil: Bahia: Ilhéus, Área Zoolog., CEPEC, Ilhéus-Itabuna km 22, x.1986, J. Delabie leg., no. 56 (1 worker) [MZSP]; Minas Gerais: Viçosa, Mata da Prefeitura. 07.i - 09.xi.1994, P.S.P. Ferreira col. (1 worker) [CDPC]; Mata do Paraíso, xii.1993-xii.1994, Ferreira, P.S.F. col. (3 workers) [CPDC]; same locality, 1997/1998, Soares, S.M. col., no. 5245 (1 worker) [CPDC]; same locality, Fragment P14, Winkler extractor, 08.iv.1998, Soares, S.M. col. (1 worker) [UFV]; same locality, same data, no. 116, Soares, S.M. col. (1 worker) [MZSP]. Santa Catarina: Blumenau, P.E. das Nascentes, $27^{\circ} 06^{\prime} 15^{\prime \prime} \mathrm{S} 49^{\circ} 09^{\prime} 14^{\prime \prime} \mathrm{W}, 20-27 . x .2000$, R.R. Silva \& F. Eberhardt cols, no. 50 (1 worker) [MZSP]; Nova Teutônia [currently Seara], $27^{\circ} 11^{\prime} \mathrm{S} 52^{\circ} 23^{\prime} \mathrm{W}$, x.1953, Fritz Plaumann col. (1 worker) [MZSP]; same locality, iv.1954, Fritz Plaumann col. (4 workers) [MZSP]; same data (1 worker) [MCZC]; same locality, xi.1957, Fritz Plaumann col. (2 workers) [MZSP]; same locality, v.1960, Fritz Plaumann col. (1 gyne) [MZSP]; same locality, iii.1971, Fritz Plaumann col., no. 7055 (1 worker) [MZSP]; same locality, iv.1972, Fritz Plaumann col., no. 7983 (1 worker) [MZSP]; same locality, xii.1974, Fritz Plaumann col., Kempf collection, no. 11627 (3 workers) [MZSP]; São Bento do Sul, A.P.A. Rio Vermelho, $26^{\circ} 21^{\prime} 51^{\prime \prime} \mathrm{S} 49^{\circ} 16^{\prime} 16^{\prime \prime} \mathrm{W}$, 30.iii-4.iv.2001, R.R. Silva \& F. Eberhardt cols, nos. 28/50 (6 workers and 2 ergatoid gynes) [MZSP]; São Bonifácio, P.E. da Serra do 
Tabuleiro, $27^{\circ} 49^{\prime} 06^{\prime \prime} \mathrm{S} 48^{\circ} 54^{\prime} 41^{\prime \prime} \mathrm{W}, 8-13 . i i i .2004$, R.R. Silva, B.H. Dietz \& N.L. Albuquerque cols, nos. 2/6/23 (5 workers) [MZSP]. São Paulo: Ubatuba, P.E.S.M., N. Picinguaba, $600 \mathrm{~m}, 23^{\circ} 17^{\prime} 54.4^{\prime \prime} \mathrm{S} 44^{\circ} 47^{\prime} 49.2^{\prime \prime} \mathrm{W}, 23 . \mathrm{i} .2006$, Scott-Santos, C.P. \& Santos, E.F. cols, no. 4 (1 worker) [MZSP].

\section{Acknowledgments}

The authors thank Brian Fisher, Erin Prado, and April Nobile (CASC) for the preparation of and permission to use the automontage figures, and Muriel Oliveira for technical support. Ricardo Kawada (MZSP) kindly prepared the images of Sphinctomyrmex marcoyi and of the S. stali gyne. Two anonymous reviewers critically read and greatly improved the manuscript. The authors are deeply indebted to Dr. Hege Vårdal (NHRS) and Dr. Larry Huldén for the invaluable information on the S. stali holotype and on the expeditions of R.F. Sahlberg to Brazil. Christian Peeters provided them with important information on ergatoids. The authors acknowledge the research grant received from Fundacão de Amparo à Pesquisa do Estado de São Paulo, Biota-FAPESP Program (no. 98/05083-0 to C.R.F. Brandão), the project PRONEX FAPESB-CNPq PNX 0011-2009, and for the grant to R.M. Feitosa (no. 07/01310-2). J.H.C. Delabie and C.R.F. Brandão are research fellows of CNPq. In accordance with section 8.6 of the ICZNs International Code of Zoological Nomenclature, printed copies of the edition of Psyche containing this article are deposited at the following six publicly accessible libraries: Green Library (Stanford University), Bayerische Staatsbibliothek, Library-ECORC (Agriculture \& Agri-Food Canada), Library-Bibliotheek (Royal Belgium Institute of Natural Sciences), Koebenhavns Universitetsbibliotek, University of Hawaii Library.

\section{References}

[1] G. L. Mayr, "Diagnosen neuer und wenig gekannter formiciden," Verhandlungen der Zoologisch-Botanischen Gesellschaft in Wien, vol. 16, pp. 885-908, 1866.

[2] T. Borgmeier, "Myrmecologische studien I," Anais da Academia Brasileira de Ciências, vol. 29, pp. 103-128, 1957.

[3] W. L. Brown Jr, "Contributions toward a reclassification of the Formicidae. V. Ponerinae, Tribes Platythyreini, Cerapachyini, Cylindromyrmecini, Acanthostichini, and Aenictogitini," Search Agriculture, vol. 5, pp. 1-116, 1975.

[4] B. Bolton, G. Alpert, P. S. Ward, and P. Naskrecki, Bolton's Catalogue of Ants of the World: 1758-2005, Harvard University Press, Cambridge, Mass, USA, 2006.

[5] E. O. Wilson, "Observations on the behavior of the Cerapachyine ants," Insectes Sociaux, vol. 5, no. 1, pp. 129-140, 1958.

[6] A. Buschinger, C. Peters, and R. H. Crozier, "Life-pattern studies on an Australian Sphinctomyrmex (Formicidae; Ponerinae; Cerapachyini): functional polygyny, brood periodicity, and raiding behavior," Psychology, vol. 96, pp. 287-300, 1989.

[7] B. Bolton, Identification Guide to the Ant Genera of the World, Harvard University Press, Cambridge, Mass, USA, 1994.

[8] R. A. Harris, "A glossary of surface sculpture," Occasional Papers of the Bureau of Entomology of the California Department of Agriculture, vol. 28, pp. 1-32, 1979.
[9] R. M. Feitosa and C. R. F. Brandão, "A taxonomic revision of the neotropical myrmicine ant genus Lachnomyrmex Wheeler (Hymenoptera: Formicidae)," Zootaxa, no. 1890, pp. 1-49, 2008.

[10] H. L. Vasconcelos and J. H. C. Delabie, "Ground ant communities from central Amazonia forest fragments," in Sampling Ground-dwelling Ants: Case Studies from the World's Rain Forests, D. Agosti, J. D. Majer, L. T. Alonso, and T. Schultz, Eds., pp. 59-70, Curtin University, School of Environmental Biology Bulletin, Perth, Australia, 2000.

[11] R. Fersch, A. Buschinger, and J. Heinze, "Queen polymorphism in the Australian ant Monomorium sp.10," Insectes Sociaux, vol. 47, no. 3, pp. 280-284, 2000.

[12] A. Buschinger and M. Schreiber, "Queen polymorphism and queen-morph related facultative polygyny in the ant, Myrmecina graminicola (Hymenoptera, Formicidae)," Insectes Sociaux, vol. 49, no. 4, pp. 344-353, 2002.

[13] W. W. Kempf, "Catálogo abreviado das formigas da Região Neotropical," Studia Entomologica (N.S.), vol. 15, pp. 3-344, 1972. 

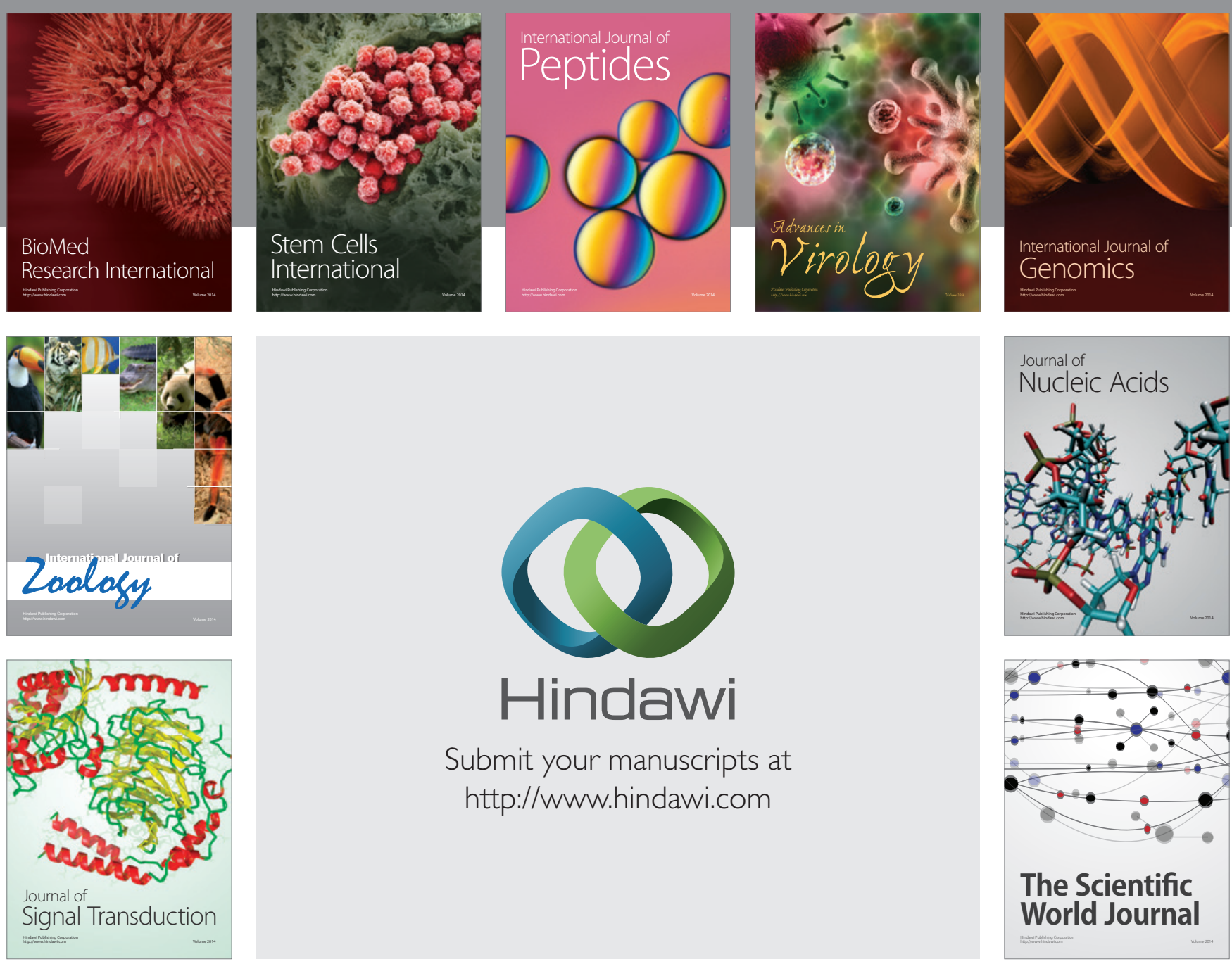

Submit your manuscripts at

http://www.hindawi.com
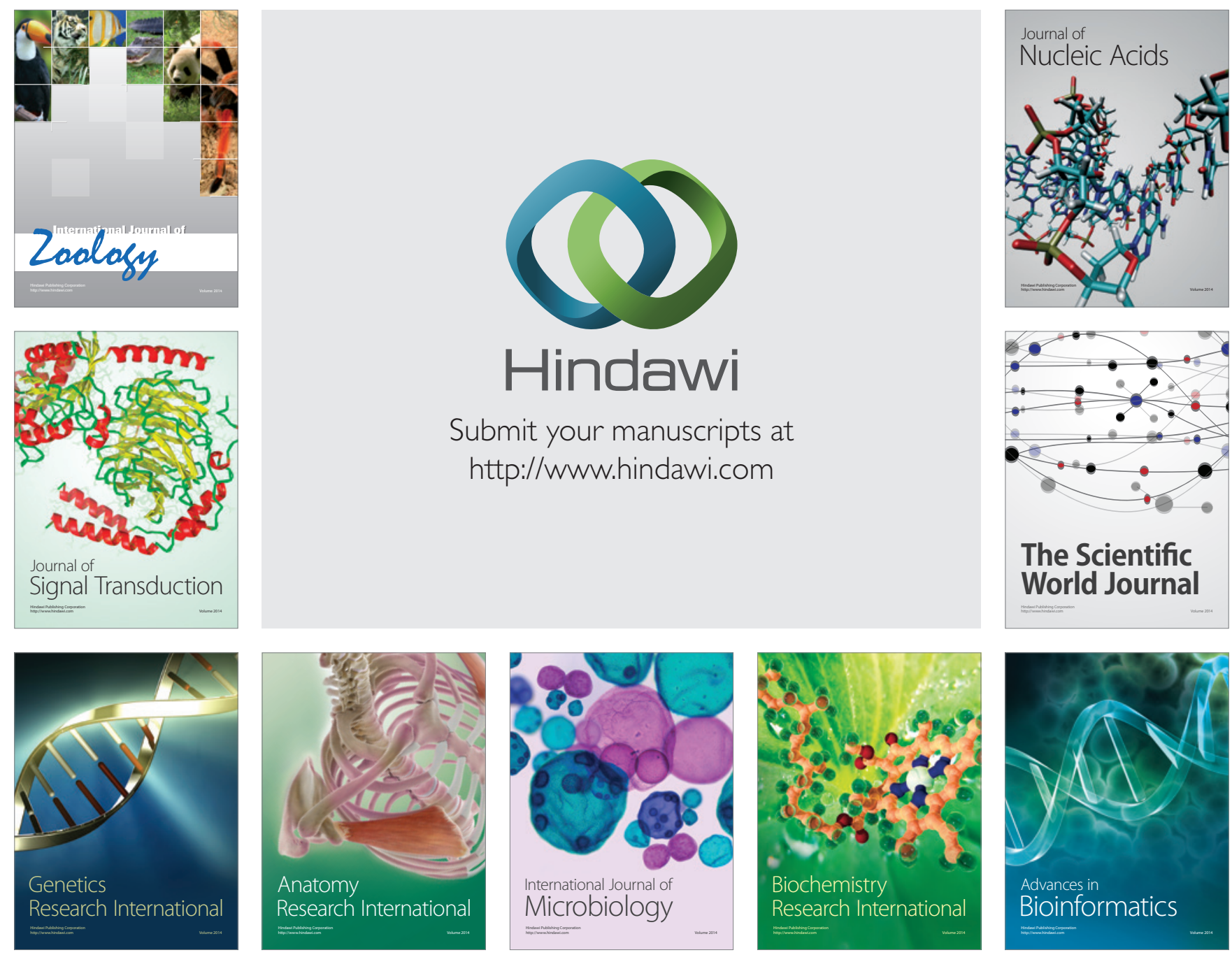

The Scientific World Journal
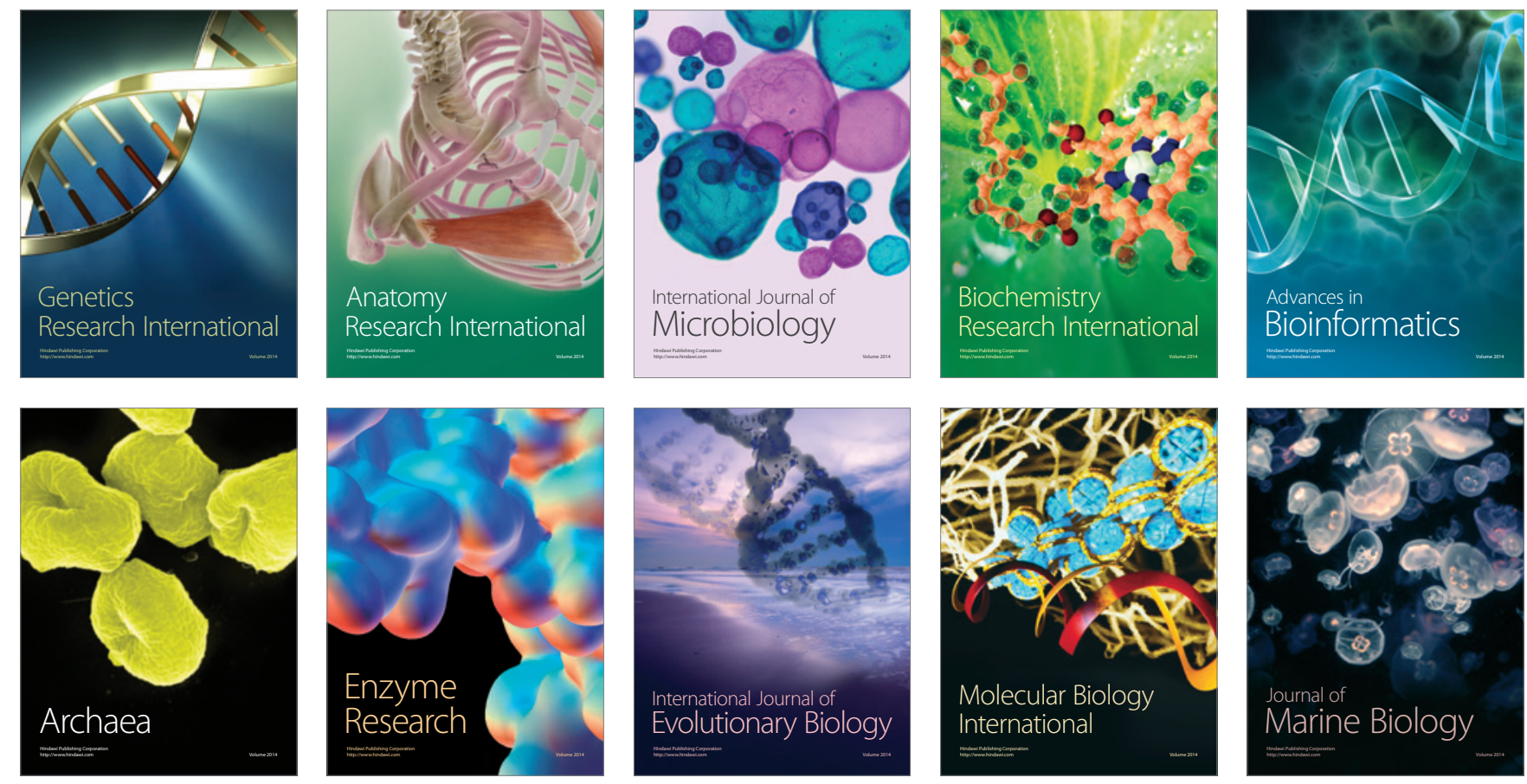